\title{
O DISCURSO POLÍTICO DA GLOBALIZAÇÃO NO CONTEXTO BRASILEIRO
}

(Political discourse of the globalization in context Brazilian)

\author{
Valney Vera Silva ${ }^{1}$ \\ (Universidade Federal do Ceará- UFC)
}

\begin{abstract}
The globalization reveals a form of abuse of power that can be perceived through the critical discourse analysis. The objective of this paper is to propose the analysis of political discourse on globalization, even with partial results, in written media relevant to the national context, using the theoretical approaches Fairclough (2003, 2006) and van Dijk (2006, 2008), taking on new rhetorical theory underlying the analysis (Reboul, 2004; Olbrechts-Tyteca, Perelman, 2006; Meyer, 2007).
\end{abstract}

Keywords: Globalization, Critical Discourse Analysis, New Rhetoric.

\section{RESUMO}

A globalização revela uma forma de abuso de poder que pode ser percebido através da análise de discurso crítica. $O$ objetivo deste artigo é propor a análise do discurso político sobre a globalização, mesmo que com resultados parciais, em mídias escritas relevantes ao contexto nacional, a partir das abordagens teóricas de Fairclough (2003, 2006) e van Dijk (2006, 2008), tendo na nova retórica a teoria que fundamenta a análise (Reboul, 2004; Olbrechts-Tyteca; Perelman, 2006; Meyer, 2007).

Palavras-chave: Globalização, Análise de Discurso Crítica, Nova Retórica.

\section{Introdução}

O tema "O discurso político hegemônico da globalização" é relevante para a Análise de Discurso Crítica (doravante ADC) devido ao seu escopo mundial, a sua complexidade como fenômeno político-econômico, e aos seus efeitos em países pobres ou em desenvolvimento; além de ser uma proposta pouco observada nos estudos do discurso no meio acadêmico.

O objetivo deste artigo é analisar o discurso político sobre a globalização no gênero notícia, no contexto brasileiro, de modo a configurar, por meio de estratégias linguísticodiscursivas, a intencionalidade velada de um discurso hegemônico neoliberal de mercado em favor dos governos mais ricos do globo. De modo a dar de conta deste objetivo torna-se necessário definir globalização em uma perspectiva sociopolítica, econômica e discursiva, no contexto brasileiro, a partir dos relatos da mídia e de bibliografia específica sobre a temática no campo das ciências políticas e econômicas; bem, como, investigar a dominação ideológica de abuso de poder a partir do discurso político sobre a globalização no gênero notícia. Esta investigação se processa nas análises linguística e discursiva do discurso político da

\footnotetext{
${ }^{1}$ Doutor e Mestre em Linguística pela Universidade Federal do Ceará (UFC). Pós doutorando pelo PNPDCAPES (UFC)
} 
globalização, no gênero notícia, a partir das categorias da retórica argumentativa, segundo a abordagem sociocognitiva de van Dijk (2003, 2006) e a pesquisa de Fairclough (2006) sobre esta temática.

Este estudo é de caráter introdutório, propondo-se a problematizar certas questões, ou ao menos lançar as bases para hipóteses posteriores. O corpus de análise é reduzido, mas significativo, de modo a fomentar mais estudos sobre o discurso da globalização. O contexto desta pesquisa sobre a linguagem e a globalização é tema do tópico a seguir.

\section{Análise de Discurso Crítica e a Globalização}

A base teórica desta investigação repousa na abordagem da ADC de Fairclough (2001, 2003, 2006) e na sociocognição proposta por van Dijk (2003, 2006, 2008, 2012). De antemão, entendemos as duas propostas como complementares para a análise do discurso político sobre a globalização econômica, através da mídia brasileira, e, por isso, expor-se-á as duas propostas de modo a observar aquilo em que contribuem para este estudo.

Uma das bases da proposta de Fairclough (2003) é a Linguística Sistêmica Funcional (doravante LSF) de Halliday (1978), de onde ele reelabora as seguintes três funções dos textos: acional, representacional e ideacional. A função acional se refere aos gêneros, a função representacional aos discursos, e a função ideacional aos estilos. Estas funções podem ser observadas simultaneamente nos textos e a relação entre elas é complexa, sendo separadas somente para fins de análise. Fairclough (2003) chama a relação entre discursos, gêneros e estilos de relação dialética.

Destacam Wodak e Meyer (2009, p.2) algumas características comuns às várias abordagens da ADC: o interesse pela linguagem no seu "exercício natural" e a relação entre a linguagem, às práticas sociais e a ideologia de dominação presentes nestes discursos. Segundo esses autores, a ADC “não é portanto interessada em investigar uma unidade linguística em si, mas em investigar o fenômeno social que é necessariamente complexo e então requer uma multidisciplinaridade e uma abordagem multimodal", na qual a linguagem faz parte. Magalhães (2005, p. 1), de modo sintético, afirma que a "análise de discurso tem como propósito o debate teórico e metodológico do discurso: a linguagem como prática social".

Fairclough (2001, 2003) e van Dijk (2006, 2008) apresentam estas mesmas características em suas abordagens, no entanto, de perspectivas diferentes. Fairclough (2008) liga a linguagem a elementos da vida social através de relações dialéticas. Sua abordagem é caracterizada pela perspectiva da mudança social, quando a Análise de Discurso 
Textualmente Orientada (doravante ADTO) se apresenta como quadro teórico para o uso na pesquisa científica social (FAIRCLOUGH, 2008, p. 89). Na ADTO, os textos são os artefatos de análise e um dos elementos fundamentais para a mudança social, numa perspectiva linguístico-semiótica. Em sua argumentação, Fairclough (2003) faz a relação entre os textos, eventos sociais, práticas sociais e estruturas sociais.

A ADTO se apresenta em um quadro tridimensional, ao estabelecer uma relação entre a linguagem e os elementos sociais. A primeira parte desta tríade na dimensão social envolve as estruturas sociais, as práticas sociais e os eventos sociais. À segunda parte desta tríade na dimensão linguística correspondem as linguagens, as ordens do discurso e os textos. Essas duas partes se relacionam da seguinte forma: as linguagens fazem parte da estrutura social, as ordens do discurso são a prática social, e os textos são os eventos sociais. Observa Fairclough, (2003, p. 24) que "há várias expressões de estruturas sociais, de práticas sociais e de eventos sociais; a relação se estabelece ao demonstrar onde a linguagem e o discurso estão neste esquema".

As estruturas sociais são entidades mais abstratas, e a linguagem se encaixa nesta qualificação por definir uma possibilidade ou uma gama de possibilidades. Os textos são os eventos sociais porque apresentam aquilo que realmente acontece. Entre as estruturas sociais e os eventos sociais há uma entidade organizacional que intermedia: as práticas sociais, que na linguagem se expressam nas ordens do discurso. A relação entre o que é possível e o que acontece, ou seja, a estrutura e o evento, é muito complexa, por isso, somente mediada pelas práticas sociais. Por sua vez, as práticas sociais são como articulações de diferentes tipos de elementos sociais que são associadas com áreas particulares da vida social (FAIRCLOUGH, 2003).

As ordens do discurso são uma rede de práticas sociais nos seus aspectos da linguagem. Os elementos da ordem do discurso são os discursos, os gêneros e os estilos. Estes elementos estabelecem o controle da variação linguística e a organização social, e por isso não são categorias puramente linguísticas, mas estão entre a linguagem e a "não-linguagem", o discurso e o "não-discurso" (FAIRCLOUGH, 2003).

Então, Fairclough $(2001,2003)$ considera que os diferentes elementos da ordem do discurso estão em relação dialética como prática social. Daí chamar sua abordagem de dialético-relacional. Neste sentido, as relações sociais são parcialmente discursivas em natureza, e o discursivo é parcialmente social nessa relação. Estas relações dialéticas envolvem sujeitos, as pessoas de um evento; envolvem suas relações de conhecimento, de conhecimento um do outro, e consequentemente relações de poder. Segundo os elementos da 
ordem do discurso, estas relações se expressam nos discursos através das representações particulares, nos gêneros por meio dos modos particulares de ação, e nos estilos através de modos particulares de identificação.

Com relação ao aspecto do poder, Fairclough (2003, p. 89) explora a investigação da mudança discursiva em sua relação com a mudança social e cultural. No que se refere à ideologia, a ADTO se baseia no conceito de hegemonia de Gramsci (1971). Um discurso hegemônico privilegia grupos sociais que detém o poder. Segundo Fairclough (2008, p. 94), o “discurso como prática ideológica constitui, naturaliza, mantém e transforma os significados do mundo de posições diversas nas relações de poder".

A segunda abordagem da ADC que embasa nosso estudo é a sociocognição de van Dijk (2003, 2006, 2008). Sua característica marcante é a interface cognitiva entre a dimensão da linguagem e a dimensão social. Tal proposta discursiva é caracterizada pelo seguinte triângulo multidisciplinar de conceitos: cognição, sociedade e discurso, em que a cognição é a interface necessária para a ADC. Van Dijk (2008, p. 10-11) adota outra nomenclatura para a ADC chamada de Estudos Críticos do Discurso (doravante ECD), por considerar que "a análise do discurso em si não é um método, mas um domínio de práticas acadêmicas, uma transdisciplina distribuída por todas as ciências humanas e sociais”. O teórico aborda as relações de poder a partir do conceito de abuso de poder e dominação, e entende a ideologia como a manifestação das crenças de um grupo social a partir de suas representações sociais. Alguns elementos caracterizam seu entendimento de ideologia: 1. uma ideologia de grupos, e não de "classes"; 2. o abuso de poder por meio da ideologia dominante; 3. a existência de grupos dominados e dominantes, com suas respectivas ideologias conflitantes; 4. a ideologia vista de uma perspectiva negativa e positiva, e não somente negativa (Van DIJK, 2003, 2006).

O primeiro elemento do triângulo multidisciplinar é a cognição, que implica a pressuposição de que a compreensão de discurso envolve não somente a representação de uma base textual na memória, mas também, ao mesmo tempo, a ativação, atualização e outros usos do chamado modelo situacional na memória episódica, isto é, a representação cognitiva dos acontecimentos, ações, pessoas e, de forma geral, a situação sobre a qual o texto se baseia (van DIJK, 2010). O aspecto cognitivo da abordagem dos ECD se apoia na teoria dos modelos mentais. Van Dijk (2003, p. 31) define modelos mentais como "as representações episódicas dos acontecimentos em que participamos a cada dia, os que atestamos (na vida real ou pela televisão) ou sobre aqueles que lemos". Os modelos mentais são subjetivos porque o modo de compreender a realidade cotidiana está diretamente relacionado à construção ou desconstrução desses modelos mentais. Eles representam a maneira de ver e entender os 84 
acontecimentos. Esse aspecto da cognição deve ser melhor compreendido nos ECD como "sociocognição", porque os modelos mentais se referem as crenças sociais comartilhadas de determinado grupo social. A ideologia de determinado grupo social é produzida, reproduzida e compartilhada a partir dos seus respectivos modelos mentais.

A representação mental das ideologias encontra-se associada, segundo a psicologia social, à memória a longo prazo, e não à memória episódica, onde se localizam as crenças individuais e as experiências diárias. As ideologias são a base da memória social compartilhada pelos grupos (van DIJK, 2003, p. 23). Elas não são socioculturais, e não se deve supor que todos as aceitam, pois, ao contrário, as ideologias surgem das diferenças de opiniões, de conflitos e lutas entre grupos sociais. Os grupos ideológicos se definem por compartilhar as mesmas ideologias. No entanto, os modelos mentais não representam somente informações pessoais, subjetivas e possivelmente enganosas dos acontecimentos que são experimentados na vida cotidiana. Os modelos mentais também apresentam "afirmações" (especificações, exemplos) de crenças mais gerais e abstratas, incluídas nas cognições sociais (van DIJK, 2003, p. 32). Percebe-se, então, o segundo elemento do triangulo teórico, o aspecto social. O modelo mental desta abordagem se atem na memória social, externada por determinado grupo social.

O terceiro elemento da abordagem multidisciplinar sociocognitiva é o discurso, produzido a partir dos modelos mentais. Como prática social o discurso não somente engloba a ideologia de uma grupo, como, também, a memória episódica deste. A inovação dessa proposta é a interface entre o elemento discursivo e o elemento social a partir da cognição, visto que o discurso envolve a representação cognitiva dos acontecimentos sociais. Os discursos explicam, defendem, legitimam, motivam, ou, de algum outro modo, "formulam" fragmentos das ideologias "subjacentes". Para van Dijk (2006, p. 19-20), os discursos não são as únicas práticas sociais baseadas na ideologia, mas, são efetivamente fundamentais em sua formulação e, portanto, em sua reprodução social. Os discursos são formas de ação e interação social, situados em contextos sociais nos quais os participantes não são somente falantes/escritores e ouvintes/leitores, mas, também são atores sociais, membros de grupos e culturas. O discurso e suas representações mentais (tais como seus significados) estão inseridos em situações e estruturas sociais (SILVA, 2011; SILVA; BAPTISTA, 2011).

As abordagens de Fairclough e van Dijk possuem diferenças e semelhanças. Para este estudo, valemo-nos das similaridades com vistas à relevância e termos de complementaridade. Dentre as semelhanças, pode-se afirmar que as propostas da ADTO e da Sociocognição são fundamentadas nas questões relacionadas ao poder. Fairclough (2001) trata da mudança social 
e van Dijk (2008) do abuso de poder e dominação. Outra semelhança é a determinação da interface entre a dimensão social e a discursiva. Fairclough (2003) propõe uma interface a partir da dialética relacional, enquanto van Dijk $(2006,2010)$ destaca a sociocognição. Com relação à abordagem ideológica observa-se outra semelhança. Van Dijk (2008, p. 24), assim como Fairclough, se baseia no conceito hegemônico de Gramsci, bem como na abordagem de Thompson (1984; 2009).

Como diferença entre estas vertentes pode-se ressaltar o aspecto metodológico. Van Dijk (2006, 2008) não se prende a um método de análise, como a LSF é para a ADTO, mas deixa em aberto o uso de uma metodologia que faça uma análise coerente; daí a adoção da terminologia Estudos Críticos do Discurso. Com relação às categorias de análise, o leque é amplo (Van Dijk, 2008), por isso, delimitamo-las na proposta da nova retórica (REBOUL, 2004; OLBRECHTS-TYTECA; PERELMAN, 2006; MEYER, 2007), por ser mais adequada aos textos em análise, e que será observada posteriormente.

O aspecto teórico-metodológico de Fairclough (2006), que adotaremos, está em sua pesquisa sobre linguagem e globalização. Como esse autor analisou textos sobre a globalização, desde uma perspectiva europeia, a partir da ADTO, acabaremos dialogando com suas categorias de análise relacionadas ao texto, especificamente a intertextualidade (FAIRCLOUGH, 2003, 2008). A partir deste encadeamento teórico-metodológico estabelecido, observaremos uma sombra aspectual do discurso da globalização no cenário brasileiro neste estudo introdutório.

\section{Discurso e globalização em pesquisa}

A relação entre globalização e linguagem possui uma farta bibliografia, que se agrupa em quatro posições: objetivistas, retoricistas, ideologistas e social construtivistas. Para Fairclough (2006), estas abordagens são incompletas, porque apresentam o discurso como uma faceta da globalização, com a função apenas de divulgação de um conceito subjetivo, como é o caso da posição objetivista. Diferentemente, Fairclough (2006) entende a globalização como um construto do discurso, e não somente como uma faceta deste. Adotamos o conceito do discurso como construto social da globalização, embora, optemos pela perspectiva sociocognitiva do discurso (van DIJK, 2003, 2008) para o estudo da globalização.

Fairclough (2006) se propõe a tratar a globalização discursivamente a partir do seu conceito de mudança social, com o fundamento ideológico em Gramsci, no que se refere à 
hegemonia, e na perspectiva da dialética entre prática social e ordens do discurso. Em suas considerações sobre as quatro posições do discurso na globalização, Fairclough (2006, p. 17) apresenta a fraqueza da posição retoricista: "Note que eles vêem a 'globalização como discursos' em termos dos efeitos da globalização ao delimitar (modificar) o repertório dos discursos disponíveis. Há uma discussão da diferença entre os 'efeitos da globalização em si' e os "efeitos de ter internalizado construções populares da globalização" (tradução minha). O teórico argumenta contra a perspectiva de Hay e Rosamond (2002) que defendem uma percepção da globalização a partir de filtros cognitivos, frames, lentes conceituais ou paradigmas, desenvolvidos no campo social, político e econômico. Fairclough (2006) considera esta perspectiva cognitiva da relação entre discurso e cognição obscura, e a rejeita em sua pesquisa.

Entre as pesquisas sobre a globalização no contexto acadêmico brasileiro, pouco se observa no que concerne à relação discurso e globalização Os estudos sobre essa temática (CHAVES, 2009; BERNARDES, 2009; MIOTELLO, 2001; COSTA, 2011; OCTAVIO, 2003) não investigam a globalização como um construto discursivo, mas como uma faceta, presente no discurso. Nossa proposta, mesmo que de modo insipiente, é apresentar, no âmbito deste trabalho, uma análise sociocognitiva do discurso político sobre a globalização, segundo van Dijk (2003, 2006). Não como a proposta retoricista, mas, considerando o discurso da globalização como construto, segundo o entendimento dos modelos mentais aliados ao discurso, numa perspectiva semântico-pragmática do discurso. Trata-se de uma proposta que busca enfocar a questão de abuso de poder e dominação, presente no discurso de globalização, a partir da temática da pobreza no nível global e da posição dos países emergentes neste processo, especificamente o Brasil.

A globalização, como uma releitura do globalismo, é estudada como uma forma de abuso de poder e dominação, como proposto nos ECD, segundo van Dijk (2006). Ainda que por outro lado, Jessop (2002) afirma o mesmo quando analisa as contradições estruturais da globalização, referindo-se particularmente à economia neoliberal da globalização como uma forma dominante. Bauman (1998) enfatiza que as novas formas de divisão social estão associadas com a globalização, além de destacar criticamente o discurso dominante da globalização.

Apropriemo-nos de conceitos propostos por Fairclough (2006) sobre o discurso e a globalização. Primeiro, que a "globalização é representada como um processo sem agentes" (FAIRCLOUGH, 2006, p. 10). Em segundo lugar, deixamos pressuposto que ao tratarmos do discurso da 'globalização', neste estudo, estamo-nos referindo ao discurso do 'globalismo' 
(STEGER, 2005), ou seja, em termos do que explica Fairclough (2006, p. 7), trata-se da estratégia no discurso de globalização que se tem tornado muito influente, demonstrando efeitos reais no processo de mudança, e que está associado aos países mais poderosos, a agências e corporações internacionais. Em terceiro lugar, enfocamos o aspecto interpretativo do globalismo, isto é, entendemos que seu aspecto chave é construir discursivamente a globalização de modo a obscurecer a proposta neoliberal, como feito primariamente a partir da liberalização e integração global dos mercados, interligado a disseminação de uma versão particular de 'democracia ocidental', com estratégias de associação (FAIRCLOUGH, 2006, p. 8). Desta forma se dá o abuso de poder e dominação de países mais ricos sobre os mais pobres.

Em quarto lugar, na perspectiva de abuso de poder, uma característica do discurso do globalismo é apresentar o Estado como incapaz de tratar a pobreza da sociedade, exceto no que se refere à limitada e inadequada proposta de "exclusão social" e de políticas para a inclusão (CAMERON, PALAN, 2004; FAIRCLOUGH, 2006, p. 20). Em quinto lugar, os discursos do globalismo trazem efeitos na construção social da globalização na forma de estratégias (JESSOP, 1999, 2002). Dentre estas estratégias, por exemplo, os discursos utilizam a retórica das narrativas neoliberais de globalização, cujo imaginário é usado para legitimar políticas não populares como o corte do salário mínimo (FAIRCLOUGH, 2006, p. 21).

Sobre o quinto conceito se fundamenta a análise discursiva, neste estudo, de modo a desvelar o discurso do globalismo a partir das figuras retóricas, como se observa nesta relação entre a globalização e a nova retórica, seção apresentada a seguir.

\section{A globalização e a nova retórica}

A análise linguístico-discursiva sobre a globalização se dará em três textos do contexto político brasileiro presentes em veículos de comunicação diferentes. O primeiro, da revista Veja (2009, n. 2108), é uma entrevista que tem como título “O liberalismo é o caminho”. Os outros textos são artigos do jornal Folha de São Paulo: "Fukuyama e o futuro da história" (25 jan. 2012) e “O capitalismo não era para sempre?” (12 jan. 2012). Todos esses versam sobre a crise político-econômica da globalização.

A análise recorre a categorias da nova retórica, segundo Meyer (2007), Reboul (2004), Olbrechts-Tyteca e Perelman (2006). Entendemos que essa é a metodologia adequada para a 
investigação discursiva desses textos. Deste modo, a ADC se relaciona a retórica pelo viés argumentativo, da persuasão e da manipulação, como prática social. Como bem observa Pinto (2009, p.37-38), “a análise de discursos, que se interessa particularmente pela disputa da hegemonia da palavra na sociedade, não deixa de ser, de certa forma, uma reflexão sobre a teoria e a técnica da retórica como prática social".

As figuras retóricas presentes nos textos aqui analisados são: a metáfora, que designa uma coisa com o nome de outra que tenha com ela uma relação de semelhança (REBOUL, 2004, p. 122); a metonímia que trata uma coisa pelo nome de outra que lhe está habitualmente associada, cujo poder argumentativo é o da denominação, uma vez que ressalta o aspecto da coisa que interessa ao orador (REBOUL, 2004, p. 121); e a litote que é o contrário da hipérbole, e possibilita figuras como: insinuação, eufemismo e ironia, das quais o eufemismo mais se sobressai (REBOUL, 2004, p. 123). Outras figuras são: a hipálage que é o deslocamento de atribuição. No discurso do globalismo este recurso retórico é recorrente. A hipérbole é a figura retórica do exagero, e se baseia numa metáfora ou numa sinédoque. Segundo Reboul (2004), sua função é dizer o que a linguagem não poderia exprimir. Neste sentido, a hipérbole "amplifica o argumento". A tapinose é uma forma de hipérbole que amplia em sentido negativo, ou seja, uma hipérbole ao contrário; frequente nos discursos a serem analisados.

Todas estas figuras retóricas elencadas acima são figuras de sentido. Possuem a característica de serem redutoras por focalizarem certo aspecto e, sobretudo, o valor do objeto que apontam em detrimento de outros. Essa é sua força argumentativa.

Outras figuras que surgirão ocasionalmente na análise são: a antítese, uma oposição retórica que se sobressai graças à repetição, é a oposição no mesmo (REBOUL, 2004, p. 127); a conglobação que acumula argumentos para uma única conclusão; e a expolição que retoma o mesmo argumento com formas diferentes (REBOUL, 2004, p. 135). Estas duas últimas são figuras de argumento.

A nova retórica caracteriza-se por sua função argumentativa. Olbrechts-Tyteca e Perelman (2006, p. 16) definem argumentação a partir do seu principal objetivo, nos seguintes termos: "toda argumentação visa à adesão dos espíritos e, por isso mesmo, pressupõe a existência de um contato intelectual". Ambos autores expandem esta definição a fim de caracterizar uma argumentação eficaz. "O objetivo de toda argumentação, [...], é provocar ou aumentar a adesão dos espíritos às teses que se apresentam a seu assentimento: uma argumentação eficaz é a que consegue aumentar essa intensidade de adesão", conforme registrado em Olbrechts-Tyteca e Perelman (2006, p. 50). Os "espíritos" a que Olbrechts- 
Tyteca e Perelman se referem configuram o logos da retórica, o que segundo Meyer (2004) é o que domina no âmbito da retórica. Por isso, a retórica não mais deve ser observada em separado da argumentação, dado seu caráter manipulador no e do discurso.

A intertextualidade, como proposta por Fairclough (2003), não é a figura central deste estudo, porém, se apresenta como eixo de conectividade para a explicação dos textos escolhidos para a análise. Alguns refletem uma óbvia menção dos mesmos documentos, enquanto outros apenas o aspecto de dialogicidade.

Fairclough (2001), para quem os “enunciados", segundo Bahktin, são "textos”, dentro da proposta da ADTO, reforça o dialogismo bahktiniano quando considera que os textos são inerentemente intertextuais, ou seja, constituídos por elementos de outros textos. Faiclough (2001) mantem, assim, a tradição de estudiosos do discurso ao fazer a distinção entre intertextualidade manifesta e intertextualidade constitutiva. A manifesta se refere à intertextualidade explícita, no seu sentido dado por Koch et. al. (2008). A intertextualidade constitutiva é a mesma implícita, a qual ele atribui uma nova nomenclatura, chamando-a de interdiscursividade. Fundamentado em Kristeva (1986), Fairclough reconhece a "inserção da história (sociedade) em um texto" e a "inserção do texto na história". A primeira relação é que o texto absorva e seja construído de textos do passado; enquanto a segunda relação mostra que o texto "responde, reacentua e retrabalha textos passados". A intertextualidade resgata essas duas relações e ressalta sua dimensão social. A intertextualidade também envolve a produção de um texto a partir de outro, por meio da transformação de textos anteriores, de modo a reestruturá-los, e assim gerar novos textos (FAIRCLOUGH, 2001, p. 135).

Considera Fairclough (2001) que a intertextualidade uma estratégia para a produção de textos e, ao ser investigada, revela a transformação e a reestruturação das tradições textuais, por um lado, e ordens de discurso, por outro. Por isso, Fairclough considera a intertextualidade de suma importância para a Análise do Discurso, como metodologia de análise. Os textos analisados, aqui, refletem uma intertextualidade temática, que estabelece a relação necessária para a análise deles. Mediante estes esclarecimentos teóricometodológicos, cabe-nos, agora, partir para a análise propriamente dita.

\section{Análise discursiva de artigos sobre a globalização}

Os textos são analisados sequencialmente, como apresentados acima, um de cada vez, para que, a partir da síntese, o aspecto ideológico de dominação seja explicitado segundo as categorias ideológicas propostas por van Dijk (2003).

90 


\section{1 "O liberalismo é o caminho"}

A entrevista "O liberalismo é o caminho", com Francis Fukuyama, apresenta a metáfora que marca o neoliberalismo no discurso da globalização. Este filósofo ficou mundialmente conhecido pelo livro "O fim da história" (1992), em que defende o fim do socialismo e a perpetuação do capitalismo neoliberal. O questionamento central desta entrevista é a continuação do capitalismo apesar da crise que enfrenta. O título da entrevista já revela uma postura de apoio ao neoliberalismo.

O vocábulo "caminho" remete ao sentido de uma única opção. Por meio da intertextualidade (FAIRCLOUGH, 2003), percebe-se o resgate que o título da entrevista faz da metáfora cristã utilizada por João no discurso de Jesus Cristo: “Eu sou o caminho, a verdade e a vida, ninguém vem ao pai senão por mim" (João 14.6). Assim como nos Evangelhos não há outra solução para o pecado do homem, também, não há outra solução para a crise econômica enfrentada pelas nações que não seja o liberalismo econômico.

A metonímia, como figura retórica, também, está bem presente nesta reportagem com a função de apagar a agentividade do discurso neoliberal hegemônico que, segundo Fairclough (2006), mascara sua real intenção de dominação. Nesta entrevista, a globalização (globalismo) está sendo designada por vários outros nomes como: liberalismo, globalização econômica, capitalismo, democracia liberal, liberalismo econômico, livre mercado. Estas metonímias escondem o agente e o sentido do globalismo ao ressaltar o aspecto de desenvolvimento e liberdade na globalização, elemento cativante ao interlocutor.

A hipélage, outra figura retórica, desloca discursivamente os principais proponentes do globalismo de seu projeto de difusão da doutrina neoliberal de mercado. Quando o entrevistador pergunta sobre o fim do neoliberalismo, Fukuyama responde assim: "O mundo estava evoluindo rumo à democracia liberal (grifo meu), e ela será o destino final. Ainda acredito nisso" (Revista Veja, 2009, p. 17); e omite quem promove e é o maior interessado pela chamada "democracia liberal". O mesmo ocorre em outras perguntas com estas: "O que o capitalismo (grifo meu) e a democracia liberal (grifo meu) precisam fazer para sobreviver à atual crise?"; "Isso não representa uma derrota do liberalismo econômico?" (Revista Veja, 2009, p. 20).

Fukuyama apresenta, no texto em questão, o neoliberalismo como resposta à crise econômica global, como se fosse uma entidade viva em si mesma: “A receita liberal, baseada no livre mercado e na globalização, ainda é a melhor alternativa para o desenvolvimento global” (Revista Veja, 2009, p. 20). Em nenhum desses trechos fica marcado o papel dos 
EUA e do Estado britânico como promotores do neoliberalismo mundial (HARVEY, 2008), resultado do efeito argumentativo da hipélage.

A hipérbole, por sua vez, também está presente nesta entrevista, especificamente como tapinose. Esta figura retórica aparece em dois trechos da entrevista argumentando em favor do discurso do globalismo:

Entre tantos efeitos globais da crise, qual mais o assusta? $O$ pior dessa história toda (grifo meu) é que, na esteira da crise, estamos assistindo a um aumento do nacionalismo econômico. Não só nos Estados Unidos, mas em todo o mundo. Seu desdobramento mais nefasto é o protecionismo. Esse movimento é um grande perigo (grifo meu). Sabemos das consequências do protecionismo. Não funcionou nos anos 1930 e não funcionará novamente (Revista VEJA, 2009, p. 20)

Quando Fukuyama responde a pergunta sobre o efeito da crise que mais o assusta, ele qualifica o "nacionalismo econômico" com a hipérbole "O pior dessa história toda", colocando-o como o principal fator da crise econômica mundial. Segundo Harvey (2008), o nacionalismo econômico e o protecionismo são um risco para o neoliberalismo, pois fazem com que países pobres se desenvolvam sem a ajuda econômica dos mais ricos. O protecionismo é definido como "nefasto" e um "grande perigo", figuras hiperbólicas que amplificam o nacionalismo econômico como a causa da crise da globalização econômica.

O segundo trecho da entrevista, em que aparece a figura hiperbólica, ressalta novamente o nacionalismo econômico como um obstáculo ao desenvolvimento: "E a América Latina? Além da crise atual, há inúmeros obstáculos para a América Latina (grifo meu). Talvez o principal (grifo meu) deles seja a atuação de um grupo de dirigentes populistas, que se opõem a qualquer iniciativa americana (grifo meu)" (Revista VEJA, 2009, p. 20).

A primeira hipérbole é "inúmeros obstáculos" que, segundo Fukuyama, coloca a América Latina (doravante AL) no centro da crise. A segunda hipérbole é "principal deles", que aponta o fator que atrasa a AL no cenário econômico global: os "dirigentes populistas". O filósofo, então, explica porque estes dirigentes são o "principal obstáculo": porque "se opõem a qualquer iniciativa americana”. Os EUA e a AL se encontram em oposição ideológica no discurso de Fukuyama, segundo a polarização Nós/Outros proposta por van Dijk (2003, 2006, 2008).

A litote, próxima figura retórica, possibilita o eufemismo que está presente neste trecho da entrevista: 
Quais são os danos até agora para os Estados Unidos? Se a economia real entrar em uma longa recessão, o que me parece bastante possível neste momento, os Estados Unidos não terão os recursos econômicos suficientes para sustentar uma série de atividades que mantêm ao redor do mundo, como a ajuda a outros governos ou as operações no Oriente Médio (grifo meu). No campo das ideias, haverá uma série de danos à imagem do país como promotor de um modelo de democracia e de capitalismo (Revista VEJA, 2009, p. 20).

A figura eufêmica minimiza os efeitos da crise nos Estados Unidos e apresenta-o como um benfeitor mundial. O prejuízo da crise para esta nação é não poder sustentar uma série de atividades no exterior. Fukuyama enumera pelo menos duas: "a ajuda a outros governos" e “as operações no Oriente Médio". A primeira litote no vocábulo “ajuda” minimiza a gravidade da atuação dos EUA ao emprestar capital financeiro aos governos pobres e emergentes, pois vela o aspecto da cobrança de juros. Esta litote também minimiza o efeito da crise nos EUA, no sentido em que esconde as fraquezas desta nação, como ficou notória no evento da "bolha imobiliária". A segunda litote está no termo "operações", que reduz o aspecto imperialista de dominação dos EUA no Oriente Médio, visto que o sintagma adequado é "guerra". Em meio a toda esta eufemização dos efeitos da crise econômica global nos EUA, Fukuyama apresenta o dano à imagem do país "como promotor de um modelo de democracia e de capitalismo". Torna-se patente que o entrevistado advoga em favor dos americanos, e que apoia o modelo neoliberal desenvolvido e propagado por eles.

A antítese, como figura retórica, mostra oposição na relação entre os Estados Unidos da América e a América Latina: "Em seu último livro, o senhor atribuiu a disparidade de desenvolvimento entre os Estados Unidos e a América Latina a suas diferenças de colonização. Por quê?” (Revista VEJA, 2009, p. 21). Esta oposição se observa em toda a entrevista entre os países ricos e pobres, EUA e países emergentes e pobres.

Duas outras figuras retóricas reforçam a argumentação de que o neoliberalismo não está em crise e nem é a causa da crise econômica global, como se observa no trecho a seguir:

Isso não representa uma derrota do liberalismo econômico? Não há nada de errado com o liberalismo. / A receita liberal, baseada no livre mercado e na globalização, ainda é a melhor alternativa para o desenvolvimento global. / Mantenho-me fiel a ela. / Milhões de pessoas deixaram a linha da pobreza nos últimos anos justamente por causa do crescimento econômico robusto no mundo. / A crise atual não foi causada por um desvio do liberalismo, mas por opções políticas equivocadas. Por décadas, seguimos um modelo que propunha a máxima desregulamentação dos mecanismos financeiros e a crença de que os mercados iriam se ajustar automaticamente a qualquer situação. Até o Alan Greenspan (ex-presidente do banco central americano) reconhece que foi um erro acreditar nisso. (Revista VEJA, 2009, p. 20) 
$\mathrm{Na}$ conglobação, primeira figura retórica deste trecho, Fukuyama apresenta uma sequência de argumentos que deslocam a questão levantada, para a conclusão em que o liberalismo não é a causa da crise econômica global. Desta forma não se responde a questão proposta, mas, através da resposta outra questão se impõe na discussão (MEYER, 2007).

Os argumentos sintetizados estão como segue: 1. negação explícita da questão ( $o$ liberalismo não tem nada de errado); 2. afirmativa enfática como única solução (o liberalismo é a melhor resposta); 3. legitimação a partir do discurso científico (visto que o entrevistado é autoridade nesta área); 4. legitimação a partir do aspecto pragmático, na dimensão social (o liberalismo retirou pessoas da pobreza); 5. conclusão (o liberalismo não é a causa da crise). A expolição também está neste trecho porque Fukuyama procede aos mesmos argumentos em formatos diferentes, como se segue respectivamente: 1. negação; 2. afirmação; 3. legitimação científica; 4. legitimação pragmática; 5. conclusão. A sequência de argumentos aponta para a conclusão óbvia de que o neoliberalismo não é a causa da crise.

Observar as palavras de Meyer (2007, p. 59) permitem-nos sintetizar a conclusão argumentativa destas figuras retóricas no tópico "As respostas que mantêm as respostas, a despeito da oposição, ou como ter sempre razão". Três estratégias apontam o aspecto retórico argumentativo da entrevista de Fukuyama:

\section{- A identidade e a diferença: o trabalho sobre a ligação pergunta-resposta}

Meyer (2007, p. 59) mostra que em um discurso argumentativo "minimizamos ou amplificamos o que queremos". As hipérboles presentes na entrevista amplificaram a causa da crise econômica: o nacionalismo econômico e o protecionismo, elementos prejudiciais à dinâmica neoliberal. As litotes, por sua vez, minimizaram os danos da crise para os EUA, ícone e promotor do neoliberalismo, e também a atuação econômica do governo americano em relação aos países mais pobres, como uma ação político-econômica desinteressada.

Com as hipérboles e as litotes, o orador se apoia nas ambiguidades e nas polissemias dos conceitos que utiliza para ofuscar o discurso neoliberal. Ao responder a questão central da entrevista, Fukuyama passa daquilo que o seu objeto de discussão é para o que ele diz que é. O neoliberalismo é a causa desta crise, mas o cientista político diz que não é. Desta forma a ligação problema-solução está invertida, o que era negativo se torna positivo. Como atesta Fairclough (2006), a globalização não possui agentes. Não foi a globalização quem causou a crise, mas “opções políticas equivocadas” (p. 20). 
- A resposta como inquestionável

"Outra maneira de neutralizar qualquer constatação consiste em fazer da resposta uma evidência” (MEYER, 2007, p. 60). As figuras argumentativas conglobação e expolição argumentam que o neoliberalismo é a resposta inquestionável à questão levantada na entrevista. A resposta é posta como "resposta para e contra tudo" (MEYER, 2007, p. 60). Nos termos de Fukuyama, o capitalismo, a democracia liberal e a globalização são a evolução do mundo, não havendo alternativa. A metáfora do "caminho" reforça a argumentação da exclusividade do neoliberalismo como resposta à crise.

\section{- A defesa pelo viés da pergunta: o deslocamento}

Esta foi a principal estratégia utilizada por Fukuyama nesta entrevista, o deslocamento. Segundo Meyer (2007, p. 60), o "ato de distanciar-se também pode evidenciar-se pelo riso, ou pela ausência de resposta, ou pela afirmação 'esse não é o problema"'. O cientista político utilizou a terceira estratégia para deslocar o alvo da questão da entrevista.

Fukuyama não tratou da questão levantada, ou seja, que o neoliberalismo era a causa da crise econômica global, mas deslocou a questão, encontrando um substituto para ela (MEYER, 2007). Isto porque não ficou aberto a discutir os questionamentos dos princípios fundamentais que o neoliberalismo defende.

Em sua argumentação, o problema não é o capitalismo e a democracia liberal no meio da atual crise mundial, mas o “estado mínimo”. Desta forma a 'globalismo' nunca está falho em sua proposta. Esta resposta de Fukuyama possui o caráter velado porque não responde diretamente a pergunta do entrevistador. De modo a suscitar outra questão mais específica: “Isso não representa uma derrota do liberalismo econômico?” (Revista VEJA, 2009, p. 20).

Segundo Meyer (2007, p. 60), uma "técnica mais sutil, mais perversa, consiste ainda em responder qualificando a pergunta de tal modo que a resposta se impõe”. Fukuyama qualifica sua resposta a partir dos argumentos apresentados nas figuras de conglobação e expolição, cuja conclusão é a excelência do neoliberalismo em meio à crise econômica global. 


\section{2 "Fukuyama e o futuro da história"}

No título deste artigo da Folha de São Paulo "Fukuyama e o futuro da história", percebe-se a intertextualidade com a entrevista da Veja com Fukuyama, analisada anteriormente. Esta foi produzida em 2009, enquanto a reportagem da Folha de São Paulo em 2012. Tendo como eixo a intertextualidade (FAIRCLOUGH, 2003) podemos fazer a comparação entre a abordagem destes dois textos.

Primeiro, observa-se que a metonímia sobre o globalismo apresenta termos que não foram destacados na entrevista da Veja, termos que desvelam o sentido da globalização como o globalismo. Estes são os vocábulos usados para descrever a globalização: o capitalismo neoliberal americano, a democracia liberal e a economia de mercado. O termo neoliberal associado à globalização econômica apresenta o real sentido proposto e propagado pelos EUA e pela Inglaterra desde 1978 (Harvey, 2008). Nesta perspectiva, a globalização como expressão neoliberal possui um agente, que não fica obscuro nestas metonímias. Esta não é uma característica do discurso do globalismo (FAIRCLOUGH, 2006).

Há poucas metáforas diretamente ligadas ao globalismo, porém, as que existem são significativas para desvelar o neoliberalismo. A primeira está no trecho que se segue:

Em 1974, o 1\% mais rico detinha 9\% da riqueza nacional. Hoje, possui quase $25 \%$. Desigualdade que uns desejam enfrentar pela via do assistencialismo e de medidas de sentido distributivo e outros preferem não enxergar ou acreditam ser um mal passageiro, a ser sobrepujado pelo retorno ao "laissez-faire" e a medidas regressivas, supostamente favorecedoras dos pobres e das classes médias pela via do "tricle-down" (gotejamento) da riqueza acumulada pelos ricos. (ABDENUR, 2012)

A metáfora está no vocábulo "gotejamento" que se refere à solução norte-americana à desigualdade que se apresenta em sua sociedade. A partir desta metáfora, o artigo expõe que o modelo neoliberal americano possui falhas, das quais uma grande é a desigualdade; ricos ficando mais ricos e pobres ficando mais pobres. Fukuyama, em sua entrevista na Veja, não destacou este como um dos efeitos da crise econômica nos EUA, mesmo o entrevistador tendo feito a seguinte pergunta: “Quais os danos até agora para os Estados Unidos?” (p. 20).

Outra metáfora acerca da globalização está no seguinte trecho:

É interessante constatar, em tal contexto, o surgimento em vários países de movimentos populistas de direita (veja-se o Tea Party nos EUA) e a ausência de um pensamento de esquerda mais amplo e integrado, capaz de colocar alternativas, ao que tem sido uma globalização em importantes aspectos 
descontrolada que ameaça encolher as classes médias nos países desenvolvidos, trazendo riscos à própria democracia representativa. (ABDENUR, 2012)

A metáfora "descontrolada" se refere à globalização, por causa dos seus efeitos prejudiciais ao crescimento da classe média dos países desenvolvidos. Entendemos que este vocábulo é uma metáfora no sentido em que, de modo implícito, põe a globalização em comparação com um veículo, ou transporte, que está fora de controle, e que, por isso, traz riscos à vida dos seus passageiros. Este campo semântico situa a globalização como algo negativo para a sociedade norte-americana. Tanto os EUA como a Europa sofrem os efeitos da crise econômica por causa do sistema neoliberal, enquanto, segundo a revista Veja, as duas potências não sofrem nenhum dano, ou este dano é minimizado.

Observa-se, também, nesse artigo, que há uma grande carga de responsabilidade sobre os EUA e a Europa pela crise econômica global, que foi posta nos governos populistas da América Latina, como se observa na entrevista dada a Veja por Fukuyama. Ao contrário do Fukuyama da Veja, o Fukuyama da Folha de São Paulo se mostra contra as elites dominantes, e não menciona os países em desenvolvimento e pobres como fator problematizador da crise.

É outro o Fukuyama que defende o questionamento dos privilégios das atuais elites dominantes, ou seja, EUA e Inglaterra. Neste artigo da Folha, não aparece nenhuma referência aos países pobres ou em desenvolvimento como parte do problema da crise econômica, muito menos se aborda o protecionismo ou as economias nacionais. Exceto a China, que é apresentada de forma positiva, com o futuro "Consenso de Pequim", um jogo de palavras com o "Consenso de Washington" que regula o neoliberalismo por décadas.

\section{3 "O capitalismo não era para sempre?"}

O último artigo a ser analisado também do jornal a Folha de São Paulo, tem como título “O capitalismo não era para sempre?”. Este também revela forte intertextualidade com os dois outros textos sobre o filósofo Francis Fukuyama. Assim como os outros textos, este artigo apresenta a tese do seu livro "O Fim da História" que defende a vitória incondicional do neoliberalismo, e sua atual posição que contradiz esta tese. As metonímias presentes neste artigo sobre o neoliberalismo, à semelhança do artigo "Fukuyama e o futuro da história", mostram denominações que expõem mais o discurso do globalismo. Estas figuras retóricas são: economia de mercado, capitalismo globalizado, democracia liberal, capitalismo e 
globalização. Estas denominações sobre o neoliberalismo não obscurecem seu real sentido, exceto "democracia liberal" devido o vocábulo que evoca o significado de "liberdade", algo positivo que vela o aspecto de dominação do neoliberalismo.

$\mathrm{O}$ aspecto da intertextualidade é bem presente nesse artigo porque ele evoca outros textos sobre o neoliberalismo. Um deles foi extraído do artigo de Fukuyama publicado na revista "Foreign Affairs", em que o filósofo apresenta sua mudança de opinião: "a corrente forma de capitalismo globalizado está erodindo a base social da classe média na qual se assenta a democracia liberal". Nesta citação, surge a metáfora "erodindo", que evoca a falha do neoliberalismo. Assim como o vento erode uma rocha, o capitalismo globalizado está destruindo a base da classe média, que é vital para a economia global. Esta é a crítica contra a tese de Fukuyama, sobre a perenidade do neoliberalismo.

O mesmo número da revista "Foreign Affairs", em que Fukuyama escreveu sobre o poder erosivo do capitalismo globalizado, reforça a preocupação com o futuro do capitalismo: “É igualmente sintomático, aliás, que o citado número da 'Foreign Affairs' contenha outros temores sobre o futuro do capitalismo/democracia". Uma metáfora reveladora neste trecho é o vocábulo "sintomático", pois, traz consigo o sentido de uma doença que está presente. O neoliberalismo é representado como uma doença, à luz dos discursos que apresentam fraquezas no neoliberalismo, como o próprio artigo de Fukuyama.

A intertextualidade continua no artigo desta análise, quando é citado o texto do professor de Assuntos Internacionais Charles Kupchan, da Georgetown University, que continua a abordar o neoliberalismo dentro do escopo do campo semântico da "doença", pois o apresenta como “doença democrática”, segundo Rossi (2012): "A globalização está ampliando o fosso entre o que os eleitores demandam e o que seus governos podem entregar. A menos que as democracias líderes possam restaurar sua solvência política e econômica, o próprio modelo que elas representam pode perder seu fascínio". A metáfora "fosso" apresenta os efeitos da globalização aumentados pela hipérbole "ampliando" que se segue. Ou seja, o neoliberalismo está distanciando o governo dos eleitores, logo, perdendo credibilidade como sistema político-econômico mundial.

Outro exemplo de intertextualidade neste artigo da Folha de São Paulo é a seção de comentários do "Financial Times", que muito repetiu o tema "crise do capitalismo" no dia anterior a publicação deste artigo. O último modelo de intertextualidade neste artigo foi a menção de trechos da sétima edição do relatório "Riscos Globais", elaborado pelo Fórum Econômico Mundial: 
Há nele pelo menos dois elementos a reforçar as preocupações de Fukuyama. O primeiro é a constatação de que "a vulnerabilidade do mundo a choques econômicos adicionais e à sublevação social causa o risco de minar o progresso que a globalização trouxe". [...] Mais importante, ao menos do meu ponto de vista, é a constatação de que, "pela primeira vez em gerações, muitas pessoas não mais acreditam que seus filhos ao crescerem gozarão de um padrão de vida mais elevado do que deles [pais]", como diz Lee Howell, responsável pelo relatório (ROSSI, 2012).

Esse relatório apresenta problemas causados pela globalização econômica: 1 . vulnerabilidade do mundo a choques econômicos; 2 . a possibilidade de estancar o crescimento da globalização; e 3. o descrédito da globalização com relação à qualidade de vida das próximas gerações. A metáfora "choque" marca o efeito negativo da globalização na economia mundial. Outra metáfora, também citada no relatório "Riscos Globais", e que está neste artigo, é "nova moléstia"; uma figura que mais uma vez apresenta o neoliberalismo no campo semântico "doença", reforçando um aspecto negativo do sistema econômico, que na década de 80 foi exaltado como perene e permanente por Fukuyama.

Um aspecto que se repete neste texto da Folha de São Paulo, como foi no outro, é a ausência da crítica aos países pobres ou em desenvolvimento, bem como às economias nacionais. O que se repete também é a menção da China como uma nação que está mantendo o crescimento da classe média, força propulsora da economia, sem a dependência do neoliberalismo ocidental. Diferentemente do modelo americano e europeu de neoliberalismo, que tem enfraquecido este setor de mercado.

\section{Considerações finais}

Segundo a proposta de Fairclough (2006), acerca do discurso da globalização ser um construto e não somente uma apresentação desta, percebemos a partir das análises linguísticodiscursivas, que as duas mídias de divulgação divergem ideologicamente. No texto da revista Veja, está presente os cinco aspectos do discurso do globalismo (FAIRCLOUGH, 2006): 1. a globalização é um processo sem agentes; 2. o discurso do globalismo é construído como a globalização; 3. o discurso do globalismo obscurece a proposta neoliberal; 4. este discurso apresenta o Estado como incapaz de tratar a pobreza, sendo a globalização a única solução; 5 . o discurso do globalismo utiliza-se de estratégias para legitimar a política econômica neoliberal. No entanto, estes mesmos elementos não estão nos artigos do Jornal Folha de São Paulo. 
O aspecto "1" é apresentado a partir de figuras como metáforas e metonímias, em que a agentividade é obscurecida. No aspecto "2", a figura mais elucidativa são as metonímias que apresentam várias denominações para o neoliberalismo. $\mathrm{O}$ aspecto "3" é uma consequência lógica da argumentação destas figuras retóricas. O aspecto "4" é um elemento que aparece polarizando ideologicamente os atores dos textos da Veja. Enquanto, o aspecto "5" reforça todas as outras estratégias retóricas que legitimam o discurso neoliberal, por exemplo, a partir das figuras de conglobação e expolição.

Há intertextualidade presente entre os textos: "O liberalismo é o caminho"; "Fukuyama e o futuro da história"; "O capitalismo não era para sempre?". Esta categoria faz a relação entre os textos de modo a demonstrar a oposição ideológica entre eles.

A intencionalidade velada do discurso presente na revista Veja apresenta elementos que o Jornal Folha de São Paulo não apresentou em seus artigos. Observa-se esta intencionalidade a partir de aspectos ideológicos destes discursos, revelados através da análise do discurso por meio das figuras retóricas.

A polarização Nós/Outros, proposta por van Dijk (2003), configura-se segundo a observação de Fairclough (2006) sobre o globalismo: Globalização (Nós) X Pobreza (Outros), ou G-20/EUA/EU (Nós) X América Latina e governos populistas (Outros). Consequentemente, o "quadrado ideológico" (van DIJK, 2003) faz-se presente na estrutura destes textos: 1. minimizar os aspectos negativos de "Nós"; 2. maximizar os aspectos positivos de "Nós"; 3. minimizar os aspectos positivos dos "Outros"; 4. maximizar os aspectos negativos dos "Outros".

Minimiza os aspectos negativos de "Nós", maximiza os aspectos negativos dos “Outros”. A partir desta polarização, observa-se que as figuras retóricas minimizam o papel dos EUA na crise econômica (a crise econômica é o tema observado nos três textos) e maximiza os efeitos da crise nos países da América Latina (somente nos textos da Veja), inclusive o protecionismo e o nacionalismo econômico característico destes países. O pior da crise é aquilo que mais afeta o neoliberalismo: o nacionalismo econômico e o protecionismo. A crise econômica mundial é um problema porque afeta os EUA e o sistema liberal, não por causa da pobreza ainda crescente no globo. Os "movimentos populistas" são enquadrados como "ilusão".

Maximiza os aspectos positivos "Nós", e minimiza os aspectos positivos dos "Outros". Os EUA foram responsáveis pelo crescimento do mundo, logo, não pode parar, pois prejudicaria todo o planeta. Os EUA é o país que "ajuda” os países mais pobres, por isso, devem ser ajudados mesmo em meio à crise econômica global. Os países Latino-americanos, 100 
e os países mais pobres, são úteis quando adotam a doutrina neoliberal, de modo a romper com o populismo, as economias nacionais e o protecionismo econômico.

A análise do discurso político desses artigos aponta para a formação de modelos mentais. Entende-se que o "quadrado ideológico" é arquitetado e constrói, por meio do compartilhamento, os modelos mentais da cognição política dos leitores destes veículos de comunicação de massa, com a finalidade de perpetuar a hegemonia do discurso neoliberal. $\mathrm{O}$ discurso como um construto se dá na dimensão sociocognitiva, na construção e posterior reprodução destes modelos mentais, como se observa na cognição política, que influencia as crenças políticas dos indivíduos e de grupos sociais, até se cristalizarem na sociedade.

Neste sentido, parece que a revista Veja, nos textos analisados, constrói o discurso velado em favor do globalismo, fomentando modelos mentais que podem influenciar a leitura e a forma de ver os atores políticos que o defendem, como os que "ajudam" os países mais pobres, de modo a manipular a aceitação desta ideologia de dominação. Por outro lado, os textos da Folha de São Paulo revelam um aspecto mais crítico em relação ao neoliberalismo, por utilizar a denominação mais desveladora, e, também, por não estabelecer o "quadrado ideológico" quando destaca os aspectos positivos dos países em desenvolvimento, como a China.

Recebido em: maio de 2014 Aprovado em: maio de 2015 prvalney@hotmail.com

\section{Referências bibliográficas}

ABDENUR, Robert. Fukuyama e o futuro da história. Folha de São Paulo, 25 de janeiro de 2012.

BERNARDES, Walkyria Wetter. A constituição identitária feminina no cenário político brasileiro pelo discurso midiático globalizado: uma abordagem discursivo crítica. Brasília: UnB, 2009. (Tese de Doutorado).

CHAVES, Helena Lúcia Augusto. Globalização, ideologia e discurso. Recife: Editora Universitária da UFPE, 2009.

COSTA, Mário de Souza. Qualificação sob a divisão capitalista do trabalho: ideologia e desqualificação. São Paulo: USP, 2011. (Tese de Doutorado).

FAIRCLOUGH, Norman. Language and globalization. New York: Routledge, 2006.

. Discurso e mudança social. Brasília: Editora da UnB, 2001. 
2003.

Analysing Discourse: Textual analysis for social research. London and New York: Routledge,

GRAMSCI, A. Selections from the Prison Notebooks. London: Lawrence \& Wishart, 1971.

HARVEY, David. Neoliberalismo: história e implicações. São Paulo: Loyola, 2008.

KOCH, Ingedore G. Vilhaça; BENTES, Anna Christina; CAVALCANTE, Mônica Magalhães. Intertextualidade: diálogos possíveis. 2. ed. São Paulo: Editora Cortez, 2008.

KRISTEVA, Julia. Word, dialogue and novel. In: MOI, T. (ed.) The Kristeva Reader. Oxford: Basil Blackwell, 1986, p. 34-61.

MAGALHÃES, Izabel. Introdução: A análise do discurso crítica. D. E. L. T. A., São Paulo, v. 21, n. especial, 2005, p. 1-9.

MENDEZ, Chico. O liberalismo é o caminho. Revista Veja, 15 de abril de 2009, edição 2108, p. 1721.

MEYER, Michel. A retórica. São Paulo: Ática, 2007.

MIOTELLO, Valdemir. A construção turbulenta das hegemonias discursivas: o discurso neoliberal e seus confrontos. Campinas, SP: Unicamp, 2001. (tese)

IANNI, Octavio. Teorias da globalização. 11. ed. São Paulo: Civilização Brasileira, 2003.

OLBRECHTS-TYTECA, Lucie; PERELMAN, Chaim. Tratado da argumentação. Lisboa: Instituto Piaget, 2006.

PINTO, Milton José. Retórica e análise de discursos. In: LOPES, Fernanda Lima; SACRAMENTO, Igor. Retórica e Mídia: estudos ibero-brasileiros. Florianópolis: Insular, 2009.

REBOUL, Olivier. Introdução à retórica. São Paulo: Martins Fontes, 2004.

ROSSI, Clovis. O capitalismo não era para sempre? Folha de São Paulo, 12 de janeiro de 2012.

SILVA, Valney Veras. O discurso político da legitimação da corrupção parlamentar nas crises políticas da era Lula. Fortaleza, UFCE, 2011. (Dissertação de Mestrado)

SILVA, Valney Veras; BAPTISTA, Lívia Márcia T. R. Discurso político: legitimação, naturalização ou banalização da corrupção? Discurso \& Sociedad, vol. 5, n.4, p. 723-748, 2011.

THOMPSON, John B. Ideologia e cultura moderna. 8. ed. Petrópolis: Vozes, 2009.

. Studies in the theory of ideology. Cambridge: Polity Press, 1984.

VAN DIJK, Teun A. Discurso e poder. São Paulo: Contexto, 2008.

Ideología y discurso. Barcelona, España: Ariel, 2003.

. Ideología: una aproximación multidisciplinaria. Barcelona, España: Gedisa, 2006.

. Political discourse and political cognition. In: CHILTON, Paul A.; SCHÄFFNER, Christina

(eds.), Politics as text and talk. Analytical approaches to political discourse. Amsterdam: John Benjamins, 2002, p. 204-236. 
Cognição, discurso e interação. São Paulo: Contexto, 2010.

WODAK, Ruth; MEYER, Michel. Methods of Critical Discourse Analysis. 2. ed. Washington D.C.: Sage, 2009. 